\title{
Twenty years of cold surface layer thinning at Storglaciären, sub-Arctic Sweden, 1989-2009
}

\author{
Alessio GUSMEROLI, ${ }^{1,4}$ Peter JANSSON, ${ }^{2}$ Rickard PETTERSSON, ${ }^{3}$ Tavi MURRAY ${ }^{4}$ \\ ${ }^{1}$ Department of Geology and Geophysics, University of Alaska Fairbanks, Fairbanks, AK, USA \\ E-mail: alessio@gi.alaska.edu \\ ${ }^{2}$ Department of Physical Geography and Quaternary Geology, Stockholm University, Stockholm, Sweden \\ ${ }^{3}$ School of Earth Sciences, Uppsala University, Uppsala, Sweden \\ ${ }^{4}$ Glaciology Group, School of Science, Swansea University, Swansea, UK
}

\begin{abstract}
This paper presents the changes in the thermal structure of the polythermal glacier Storglaciären, northern Sweden, over the 20 year period 1989-2009 derived by comparing maps of the depth of the englacial transition between cold ice (permanently frozen) and temperate ice (which contains water inclusions). The maps are based on interpreted ice-penetrating radar surveys from 1989, 2001 and 2009. Complex thinning of the cold layer, first identified between 1989 and 2001, is still ongoing. A volume calculation shows that Storglaciären has lost one-third of its cold surface layer volume in 20 years, with a mean thinning rate of $0.80 \pm 0.24 \mathrm{~m} \mathrm{a}^{-1}$. We suggest that the thinning of the cold layer at Storglaciären is connected to the climatic warming experienced by sub-Arctic Scandinavia since the 1980s and we argue that repeated ice-penetrating radar surveys over the ablation area of polythermal glaciers offer a useful proxy for evaluating glacier responses to changes in climate.
\end{abstract}

\section{INTRODUCTION}

The effect of climate change on glaciers is a major concern since glacier run-off directly affects sea level (Radić and Hock, 2011) and water resources (Huss, 2011). Climate change also affects the glacier system directly, for example by changing the thermal structure of Arctic and sub-Arctic glaciers (e.g. Rabus and Echelmeyer, 2002; Pettersson and others, 2007). Very few observations exist of how the thermal regimes of ice masses are responding to climatic warming over the past few decades. Such a response is particularly important for two reasons: (1) temperature changes can be used as an additional proxy for understanding climate change in glaciated areas (Blatter, 1987; Blatter and Kappenberger, 1988; Rabus and Echelmeyer, 2002; Vincent and others, 2007; Barrett and others, 2009; Gilbert and others, 2010); and (2) rising englacial temperatures in steep glaciers, currently frozen to the mountains on which they reside, can reduce the friction at their beds, increase ice avalanching and thus constitute an increasing hazard (Le Meur and Vincent, 2006; Huggel, 2009).

Here we report measurements of changes in thermal regime collected during the last 20 years on the $3 \mathrm{~km}^{2}$ Storglaciären, northern Sweden (Fig. 1a). This valley glacier is well studied, with a very long (post-1946) continuous massbalance series (e.g. Holmlund and others, 2005) as well as a number of detailed studies of glacier hydrology (e.g. Fountain and others, 2005) and glacier dynamics (e.g. Iverson and others, 1995). At Storglaciären, several studies of englacial temperature combined with ice-penetrating radar measurements have revealed that the glacier is largely temperate apart from a cold, permanently frozen, surface layer overlying the temperate core in the ablation area (Fig. 1b) (Schytt, 1968; Hooke and others, 1983; Holmlund and Eriksson, 1989; Pettersson and others, 2003, 2004; Gusmeroli and others, 2010). Much of the ice is kept temperate by refreezing of springtime melt as it percolates into firn in the accumulation zone; and this warm ice is then advected downwards and into the ablation zone. At the surface of the ablation zone, however, spring and summer melt run off the glacier quickly, rather than refreezing, and this allows the layer of cold ice to persist (Hooke and others, 1983). Different thermal structures and their occurrence in various glaciated areas are discussed by Blatter and Hutter (1991).

The boundary between cold and temperate ice is a prominent englacial transition known as the cold-temperate transition surface (CTS; Fig. 1b) (Hutter and others, 1988; Blatter and Hutter, 1991; Pettersson and others, 2003). Other than being a thermal boundary, the CTS also represents a hydraulic boundary for intra-granular water, separating the water-free region from the temperate region which contains small volumetric percentages of water (up to $\sim 1 \%$ ) (Pettersson and others, 2004; Gusmeroli, 2010). The CTS in glaciers can be mapped using ice-penetrating radar (Holmlund and Eriksson, 1989; Björnsson and others, 1996; Ødegård and others, 1997; Murray and others, 2000; Pettersson and others, 2003; Gusmeroli and others, 2010). The principle of the technique is that the presence of water bodies in the temperate ice causes energy to be reflected or backscattered. The CTS of Storglaciären was mapped using radar in 1989 (Holmlund and Eriksson, 1989) and 2001 (Pettersson and others, 2003). A comparison between the two surveys revealed a substantial and complex thinning of the cold layer, which lost about $22 \%$ of its average thickness in 12 years (Pettersson and others, 2003). These changes at Storglaciären were quoted in the 2007 Intergovernmental Panel on Climate Change (IPCC) report as evidence of warming in the Arctic (Lemke and others, 2007). In this paper, we add new observations of the extent of the cold layer of Storglaciären for the year 2009, using new data acquired from ice-penetrating radar and ice-temperature measurements during the spring of that year. Combining our results with those from 1989 (Holmlund and Eriksson, 1989) and 2001 (Pettersson and others, 2003), we present the first time series of changing thermal regime at Storglaciären and interpret the observed changes in the light of contemporary regional climate change and mass-balance measurements. 


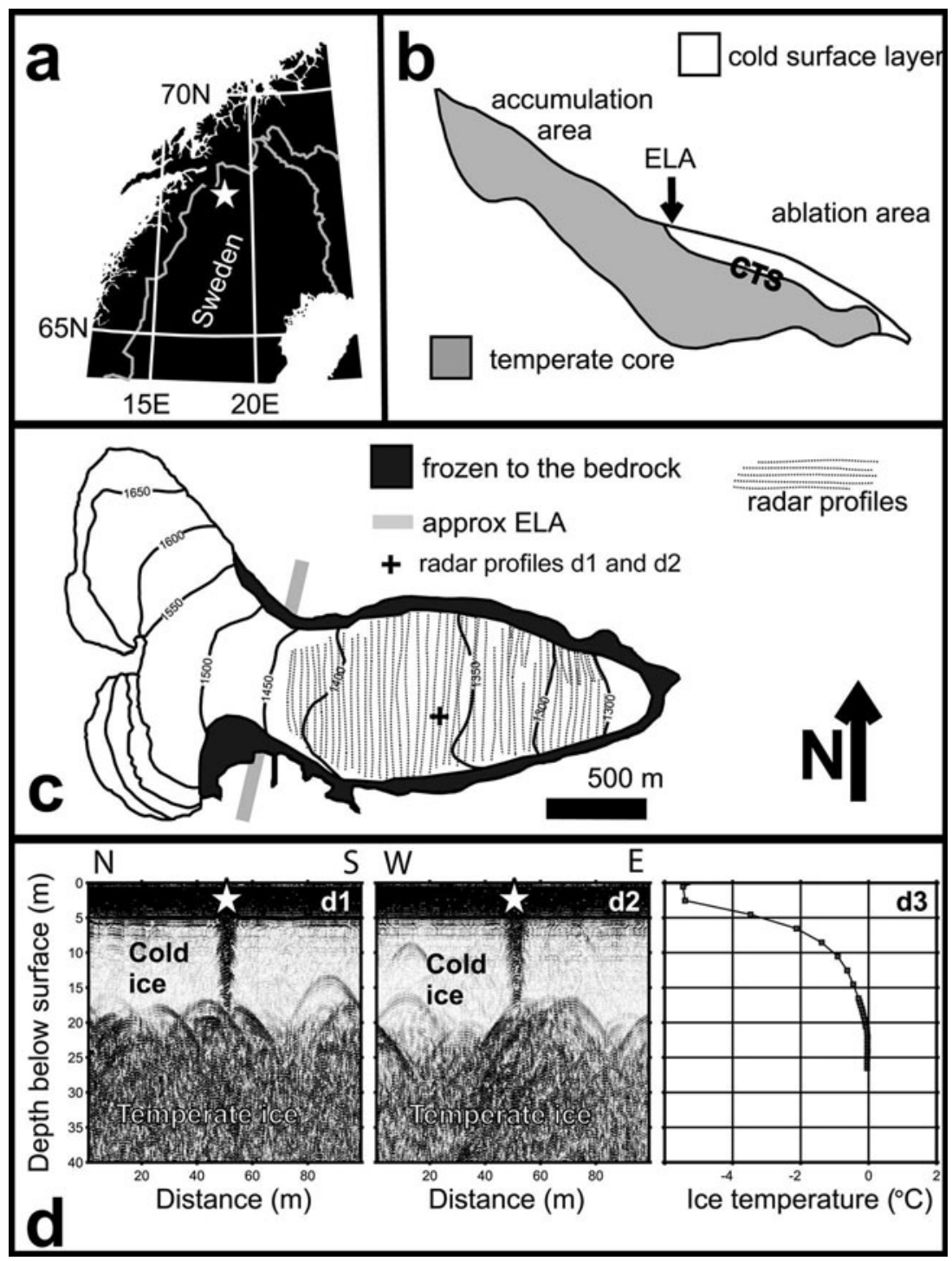

Fig. 1. Location maps and comparison between $100 \mathrm{MHz}$ radar-derived and thermistor-derived thermal structure of Storglaciären. (a) Location of Storglaciären. (b) Sketch of englacial thermal structure (adapted from Aschwanden and Blatter, 2009) with indication of the equilibrium-line altitude (ELA) and the cold-temperate transition surface (CTS). (c) Map of the glacier. (d) Direct comparison between radarderived $(\mathrm{d} 1, \mathrm{~d} 2)$ and temperature-derived $(\mathrm{d} 3)$ thermal structure of the glacier. From the thermistor data $(\mathrm{d} 3)$ the melting isotherm is reached at $21 \mathrm{~m}$. The white star indicates the position of the thermistor string, which is also where the two perpendicular radar profiles intersect. The scatterers in the cold ice observed beneath the stars are not due to temperate ice but are the remains of the drillhole which hosted the thermistor string.

This study parallels recent similar efforts investigating the link between climate and the thermal regime of Arctic glaciers (e.g. Wohlleben and others, 2009; Rippin and others, 2011).

\section{2009 RADAR MEASUREMENTS}

We acquired two sets of measurements using the same radar system: (1) 60 continuous radar profiles which were interpolated to obtain the 2009 CTS map, and (2) two stop-andgo additional surveys at a location where a thermistor string was present in the ice. The former set of measurements allowed quick mapping of the CTS, whereas the latter was used for a direct, unambiguous comparison between the radar-derived CTS and the thermistor-derived CTS.

\subsection{Radar acquisition and processing}

Ice-penetrating radar data for the 2009 cold-layer map were acquired using a commercially available Malå Geoscience radar system with $100 \mathrm{MHz}$ unshielded antennas. Forty-eight radar profiles were collected by pulling the radar with a snow scooter (Fig. 1c) during April 2009. The data were collected in the spring, in order to avoid unnecessary noise that may occur in the summer when meltwater is present. Coverage was increased in steep and crevassed areas by acquiring 12 additional profiles using the same system manually on skis. Survey position was acquired using a Garmin hand-held GPSMap 60CS coupled to the radar system, storing the position of radar traces every $2 \mathrm{~s}$ to $\sim 40$ radar traces. The spacing between subsequent radar lines was about 30-40 m on average, much denser than any previous survey.

Radar data processing was minimal and consisted of time-zero correction, low-frequency filter (dewow) and time-depth conversion using a constant radar wave speed of $0.168 \mathrm{~m} \mathrm{~ns}^{-1}$. This speed is typically applied in radioglaciological studies and is consistent with borehole radar measurements in the ablation area (Gusmeroli and 
P22

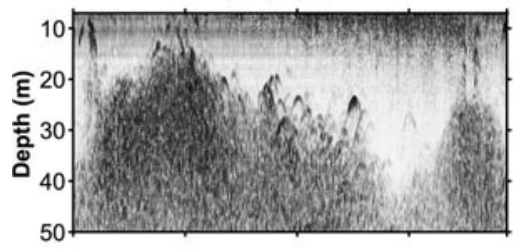

P34

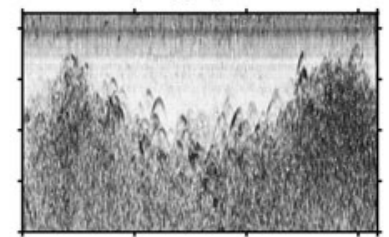

P42

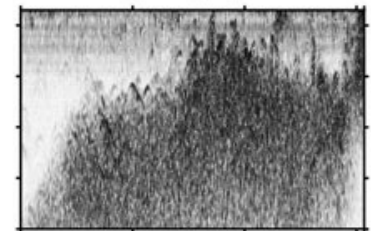

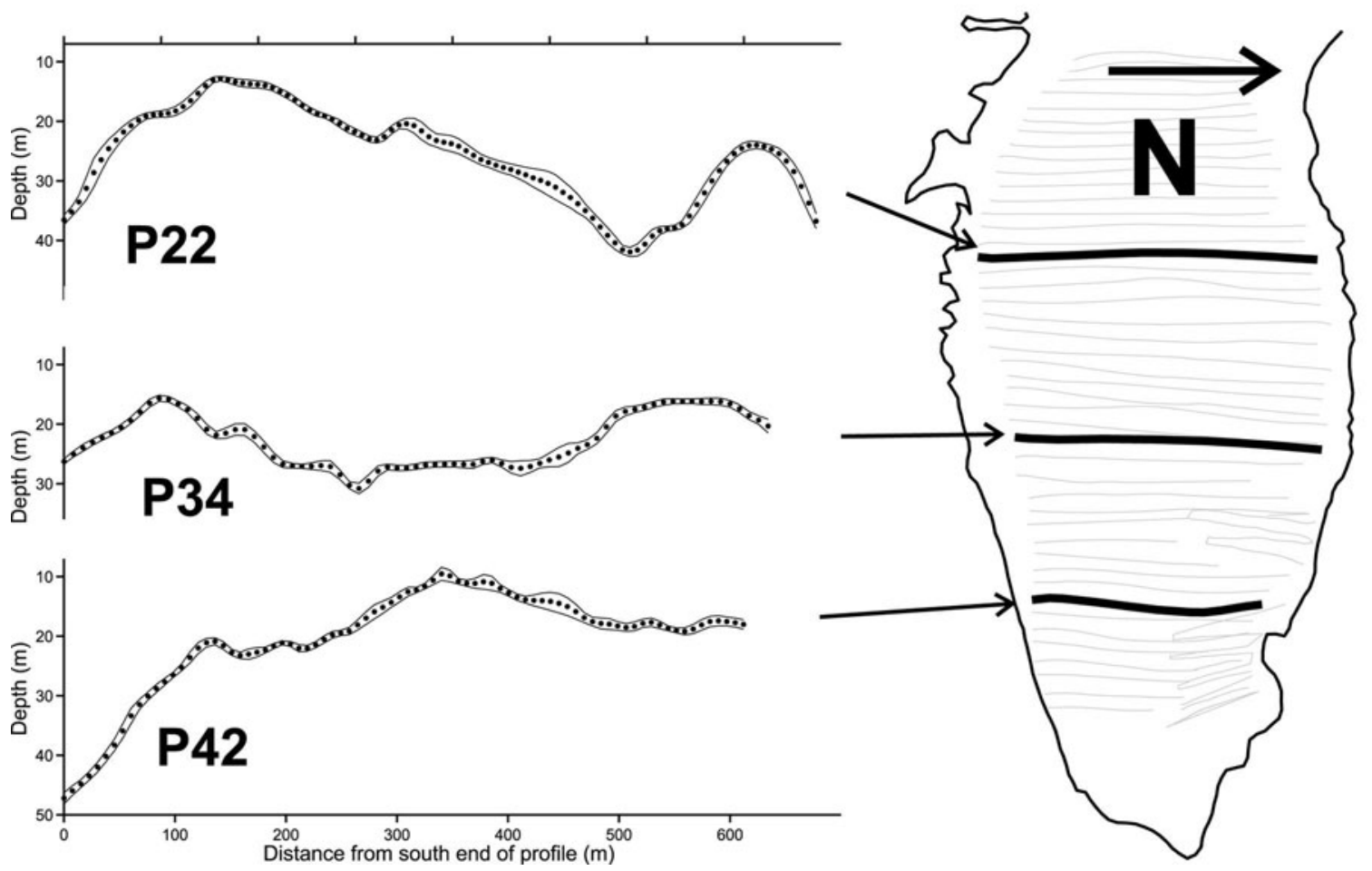

Fig. 2. Spatial variability of the CTS depth and representative examples of CTS depth estimates from $100 \mathrm{MHz}$ radar profiles acquired in April 2009. CTS values and their estimated uncertainty are indicated by black circles and solid lines respectively.

others, 2010). Tests showed that the depth error introduced by any uncertainty in radar wave speed is $\pm 0.3 \mathrm{~m}$ when compared to speeds measured with borehole radar in the cold ice of Storglaciären $\left(0.168 \pm 0.002 \mathrm{~m} \mathrm{~ns}^{-1}\right.$; Gusmeroli and others, 2010).

Migration tests were conducted on sample radargrams (Gusmeroli, 2010). However, the final results presented in this paper were extracted from unmigrated radargrams for two reasons: (1) migration only managed to collapse hyperbolic events and did not change the interpreted CTS depth (Gusmeroli, 2010), and (2) the previous surveys of the CTS of Storglaciären (Holmlund and Eriksson, 1989; Pettersson and others, 2003) obtained their results from unmigrated data.

\subsection{Radar-temperature-profile comparison}

A temperature profile, obtained using a string of thermistors (Gusmeroli and others, 2010) was used to compare the thermistor-derived and radar-derived CTS. The comparison was obtained using the two radar lines shown in Figure $1 \mathrm{~d}$. These profiles were acquired in April 2009 at the thermistor location (Fig. 1c). The two radar lines were perpendicular up and across glacier, with the thermistor string, indicated by an ablation stake supporting the data logger, located at the centre. We used a stop-and-go method and held the radar system motionless at $0.5 \mathrm{~m}$ sampling intervals. The length of each profile was $100 \mathrm{~m}$.
Each radargram clearly shows two regions: an upper region which is transparent to the radar energy, and a lower region with a distinctly higher level of backscattered radar energy (Fig. 1d1 and d2). The boundary between transparent and scattering-rich ice is interpreted as the CTS. At this location the CTS undulates in the radargrams, but is within the depth range $20 \pm 2 \mathrm{~m}$, in good agreement with the melting isotherm detected at $21 \mathrm{~m}$ depth by the thermistor string (Fig. 1d3).

\subsection{CTS mapping}

By tracing the boundary between transparent and scatteringrich ice on all 60 radargrams, we obtained a detailed series of CTS depth profiles (Fig. 2), which were interpolated as in the previous study (Pettersson and others, 2003) using ordinary kriging (Isaaks and Srivastava, 1989). Ordinary kriging is a commonly applied technique for interpolating spatially discontinuous datasets. We assessed errors introduced by hand-tracing the CTS for each profile 30 times and we obtained a standard deviation of $\sim 0.8 \mathrm{~m}$ in mapping the CTS. As in the previous study (Pettersson and others, 2003), the interpolated map was corrected for the presence of snow using the spring 2009 snow-cover data collected on the glacier by Tarfala Research Station.

Both this study and Pettersson and others (2003) considered that the manual picking of the CTS boundary is limited by the subjectiveness of tracing the boundary. 
Pettersson and others (2003) assessed the problem by digitizing the CTS a few months apart from randomly selected profiles. The comparison between the different digitizations deviated by $\pm 1.5 \mathrm{~ns}$, which yields $\pm 0.25 \mathrm{~m}$ in depth. In the present study, instead, each profile was digitized 30 times and the CTS thickness presented in the map was the average of each 30 digitizations, with average depth uncertainty (estimated with the standard deviation) of $\pm 0.8 \mathrm{~m}$. These uncertainties are minor if compared to the depth at which the melting isotherm corresponds to the picked CTS ( $\pm 1 \mathrm{~m}$ in Pettersson and others (2003) and $\pm 2 \mathrm{~m}$ in this study).

The frequency dependence of the CTS detection is an important issue that deserves further exploration. It is important to observe that the 1989 and the 2001 CTS map were derived at a frequency of $345 \mathrm{MHz}$ whereas the most recent map was obtained at a frequency of $100 \mathrm{MHz}$. The direct comparison of the performance of the two systems in detecting the melting isotherm $( \pm 1$ and $\pm 2 \mathrm{~m}$ for Pettersson and others (2003) and this study respectively) does not support the presence of any system-induced misinterpretation: the measured melting point at the thermistor string closely agrees with the radar CTS in both studies. However, we note that it is still unclear how the continuous-wave stepped-frequency (CWSF) ground-penetrating radar (GPR) systems (used in Pettersson and others, 2003) compare to the pulse GPR system used in this study. For example, Pettersson (2005) who compared the CTS depth recorded at different frequencies $(145,345,800$ and $1150 \mathrm{MHz})$ found that the CTS detected by the CWSF at a frequency of $145 \mathrm{MHz}$ was on average $\sim 5 \mathrm{~m}$ deeper than the $345 \mathrm{MHz}$ CTS (which in turn was in the $\pm 1 \mathrm{~m}$ range from the melting isotherm). Such a discrepancy at lower frequencies is not observed by our $100 \mathrm{MHz}$ pulse system (the radar-derived CTS deviates $\pm 2 \mathrm{~m}$ from the melting isotherm). A comparison between a temperature profile and a series of pulse-type and CWSF GPR surveys would allow better understanding of this matter.

The positioning error for the three different surveys was $\pm 21, \pm 1$ and $\pm 10 \mathrm{~m}$ for the three epochs. The best survey was obtained in 2001, when the radar system was connected to the differential GPS. However, correlogram analysis of CTS maps shows that the uncertainties in positioning only introduce serious errors in the CTS depth if the slope of the CTS is large (Pettersson and others, 2003). Typically, CTS depth measurements within the position uncertainty of $\pm 21 \mathrm{~m}$ are very similar (Pettersson and others, 2003). This is because the CTS is a relatively smooth surface (the CTS over $100 \mathrm{~m}$ varies only $\pm 2 \mathrm{~m}$ which is well within our stated error of $\pm 3 \mathrm{~m}$ ). Thus, following Pettersson and others (2003) the uncertainty in CTS depth introduced by positioning is assumed to be $\pm 1 \mathrm{~m}$ in 1989, negligible in 2001 and $\pm 0.5 \mathrm{~m}$ in 2009 . To summarize we present our results by assuming an overall, worst-case-scenario uncertainty in the CTS map of $\pm 3 \mathrm{~m}$ ( $\pm 2 \mathrm{~m}$ of uncertainty in the CTS detection and $\pm 1 \mathrm{~m}$ of combined factors such as tracing and positioning).

\section{THERMAL CHANGES}

The cold-layer thicknesses as mapped by Holmlund and Eriksson (1989), Pettersson and others (2003) and in this study are shown in Figure $3 \mathrm{a}, \mathrm{b}$ and $\mathrm{c}$ respectively. The thinning trend reported by Pettersson and others (2003) has continued since the cold layer was substantially thicker in
2001 than 2009 (Fig. 3). In detail, the thicker area (A in Fig. 3a) toward the northern side of the glacier, which was $\sim 60 \mathrm{~m}$ thick in 1989 (Fig. 3a), lost $\sim 50 \%$ of its thickness and in 2009 was $<35 \mathrm{~m}$ thick (Fig. 3c). Such a high thinning is, however, not observed everywhere in the ablation area. For example, the thin portion in 1989 (B in Fig. 3a) with values of thinning of $\sim 10 \mathrm{~m}$ thinned less than elsewhere. Changes in cold-layer thickness for all the epochs are shown in Figure 3d-f.

We estimated the rate of thinning by undertaking a simple volume calculation from the three maps. In Figure 4 we show the first time series of thermal changes at Storglaciären. From this calculation (Fig. 4) we obtained coldice volumes of $44.2,34.9$ and $28.2 \pm 3.4 \times 10^{6} \mathrm{~m}^{3}$ for 1989 , 2001 and 2009, respectively (Fig. 4). These results suggest that the cold surface layer of Storglaciären has lost about one-third of its volume in 20 years (Fig. 4). The error bars we show in Figure 4 were calculated by assigning at each CTS data point an error of $\pm 3 \mathrm{~m}$. The volume calculation shown in Figure 4 only helps in identifying thermal changes and does not attempt to evaluate the general mass loss from the glacier in the period.

\section{DISCUSSION}

\subsection{Snow cover, ablation and cold-layer thickness}

The map of cold-layer thickness presented in this study shows a distinct spatial variability (Fig. 5a). Such a spatial variability is directly linked to the net mass balance of the glacier (Pettersson and others, 2003, 2007) and is a result of a combination of factors: (1) snow accumulation during winter (spatially variable), and (2) summer melting which, at first approximation, varies only with altitude. The general pattern of cold surface layer thickness closely follows the snow thickness pattern which remained, as a first approximation, largely unchanged for the two measurement periods (Fig. $5 \mathrm{~b} 1$ and b2). Figure 5c1 shows a schematic cross section through a portion of the ablation area. The presence of a spatially variable snow cover implies that, for the same melting rates, there will be differential removal of glacier ice since a thicker snowpack protects the ice from melting (Fig. 5c2). The result is that a thicker cold surface layer will persist in an area of thicker snow cover (Fig. 5c3). A counteracting factor which thickens the cold layer is the downward migration of the CTS (Pettersson and others, 2007). The presence of a temperature gradient at the CTS results in heat being conducted away from it and the freezing front to migrate downward. This results in a thickening of the cold layer (Fig. 5d2). The downward migration of the CTS is shown schematically in Figure $5 \mathrm{~d} 1$.

The thickest and thinnest parts of the cold layer ( $x$ and $y$ respectively in Fig. 5a) generally correspond to the average snow accumulation pattern over the glacier (Fig. 5b1 for 1989-2001 and Fig. 5b2 for 2001-09). For a similar melting rate, an area with thicker snow cover will have a thicker cold surface layer because the annual thinning of the layer will only start once the snow cover is completely removed. This is clear by looking at the evolution of the transient snowline over a summer (Fig. 6). The thinnest layer is found in the first snow-free areas (Fig. 6). In these areas the ice surface is directly exposed to ablation earlier in the season, so the ablation-induced annual thinning of the cold surface layer is higher. The thicker layers are found in areas that remain 

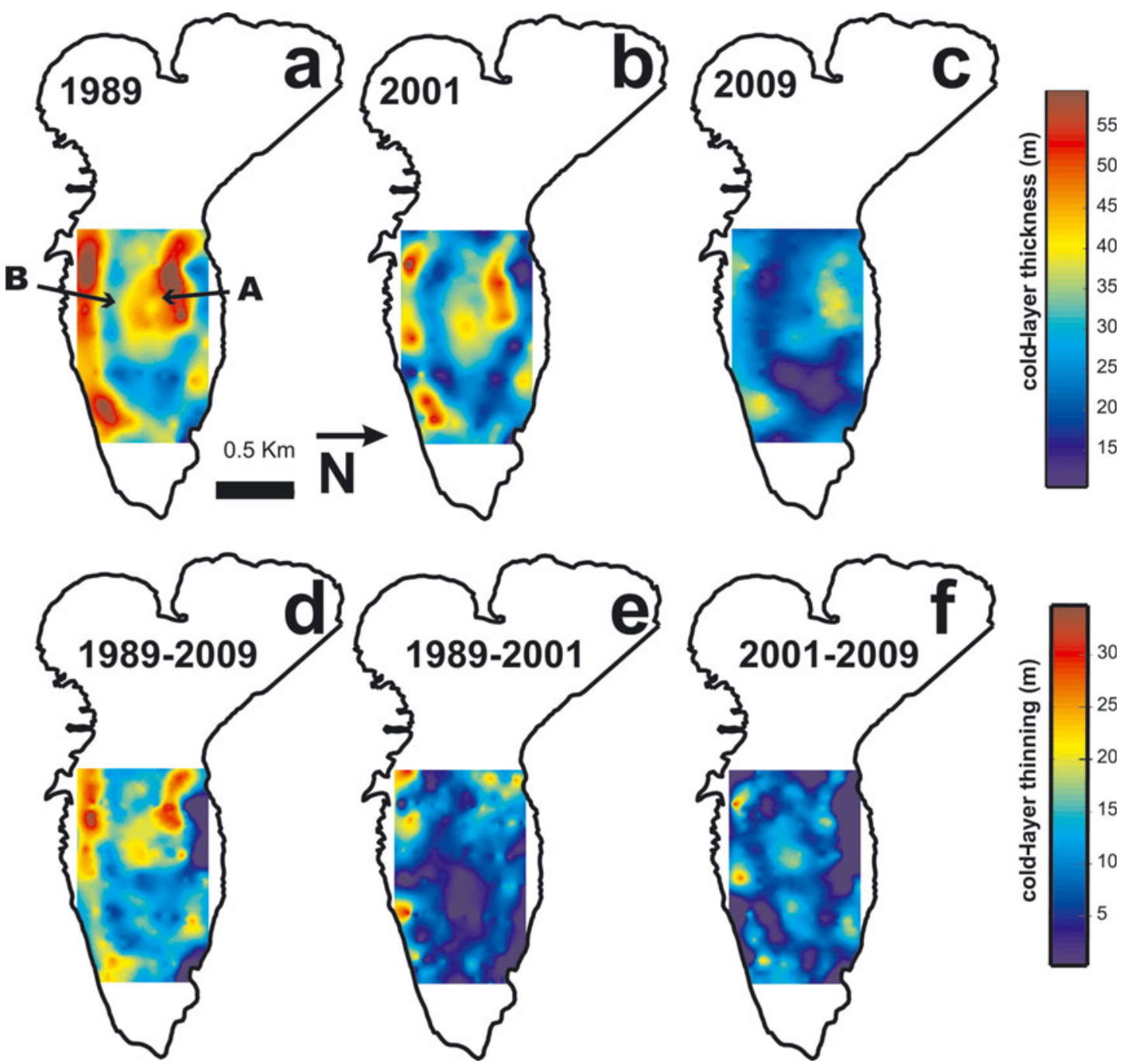

Fig. 3. Maps of cold-layer thickness and cold-layer thinning at Storglaciären for 1989, 2001 and 2009. (a-c) Cold-layer thickness in (a) 1989 (b) 2001 and (c) 2009. (d-f) Change in cold-layer thickness for (d) 1989-2009, (e) 1989-2001 and (f) 2001-09. The surveys were in the ablation area of the glacier. A and B refer to portion of the cold layer discussed in the text.

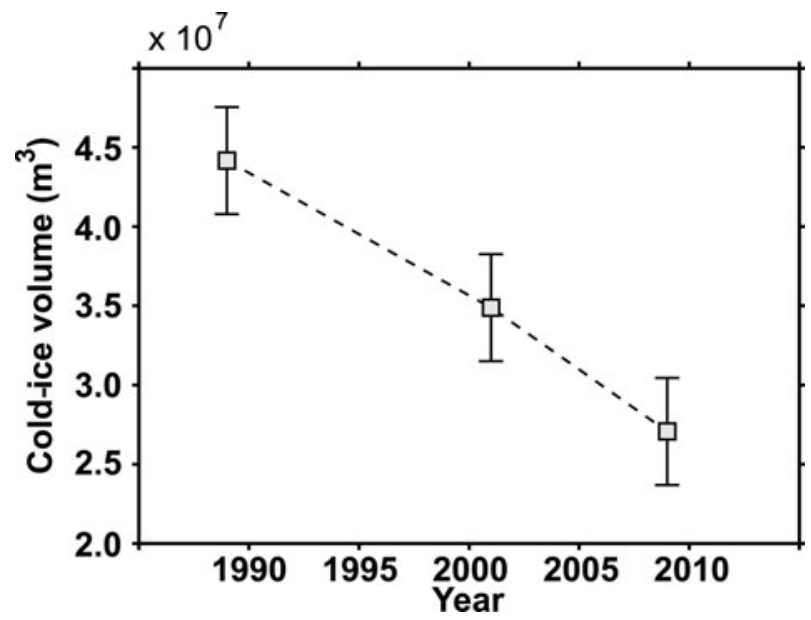

Fig. 4. Cold-ice volume changes at Storglaciären; volume is calculated from the maps of cold-layer thickness shown in Figure 2. The cold surface layer of Storglaciären has lost about one-third of its volume in 20 years. Changes in this figure are for the ablation area of the glacier. The error bars were calculated by considering a total error in cold-layer thickness of $\pm 3 \mathrm{~m}$. The total error is estimated from a combination of different factors (CTS detection, CTS tracing and GPR positioning). snow-covered for a longer time (Fig. 6). In this respect a map of the cold layer might reveal and bring additional information on the spatial variability of snow cover over a glacier.

There are, however, many other factors that can be considered as causative processes for the spatial variability of the cold-layer thickness. These include longitudinal advection of ice flow from the two different accumulation basins and the spatial distribution of crevasses (Jarvis and Clarke, 1974). Since the scope of this paper is to report the continuation of the cold-layer thinning we redirect the reader to Pettersson and others (2007) for a detailed discussion on the dynamics of the CTS in polythermal glaciers.

\subsection{Thinning of the cold surface layer at Storglaciären 1989-2009}

From our analysis we can observe that the cold surface layer of Storglaciären has been experiencing a continuous thinning, and volume loss, at a rate that seems largely unchanged since 1989 (Fig. 4). The overall decrease of 22\% of average thickness observed by Pettersson and others (2003) agrees very well with the volume change observed in this study. From the linearity of the loss it can be hypothesized that the cold layer is slowly but consistently thinning at an average rate of $0.80 \pm 0.24 \mathrm{~m} \mathrm{a}^{-1}$. 


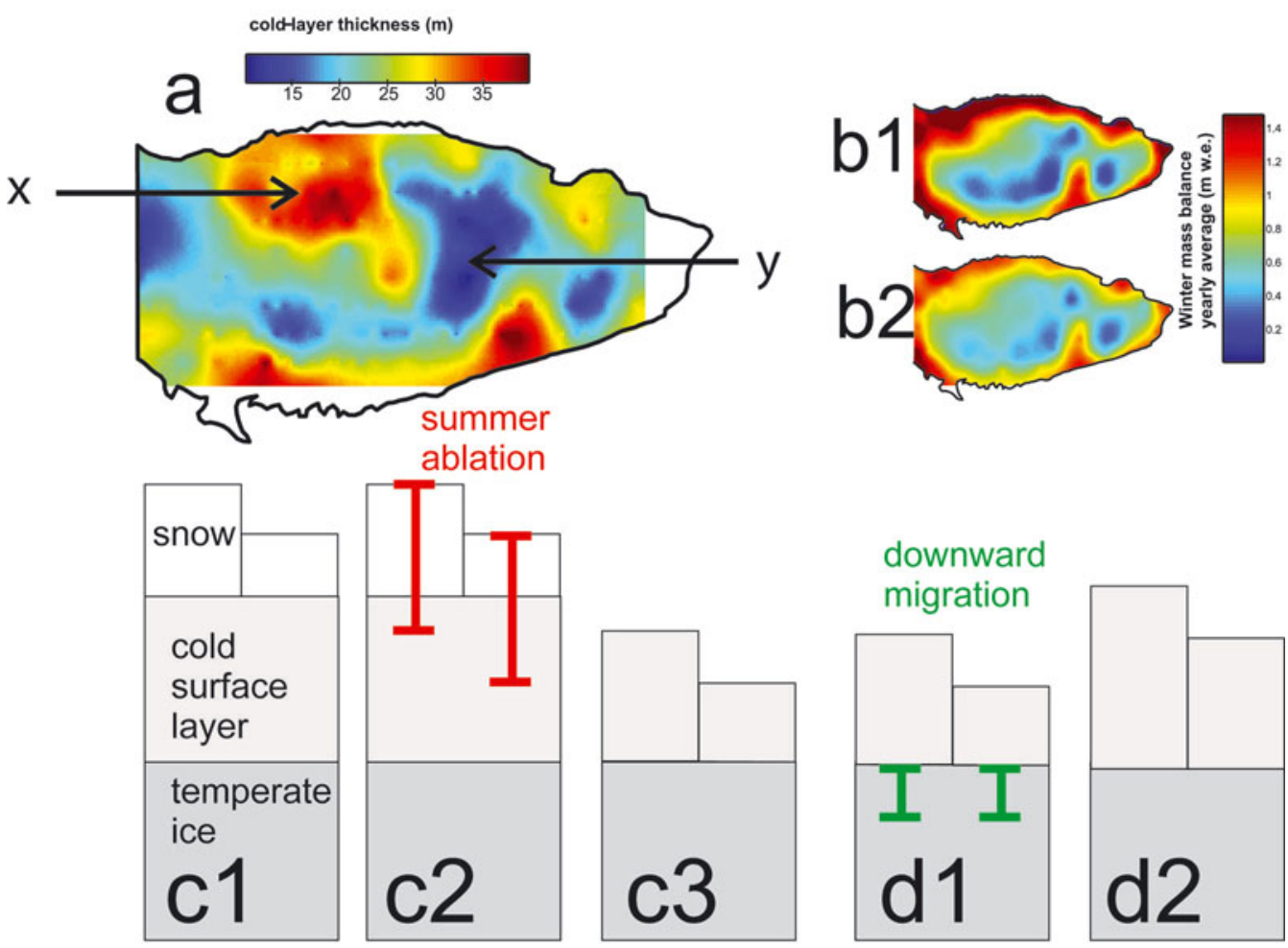

Fig. 5. (a) Cold surface layer thickness map acquired in April 2009 at Storglaciären. (b1, b2) Yearly averaged winter mass balance for the periods (b1) 1989-2001 and (b2) 2001-09. (c1-c3) Schematic evolution of cold-layer thickness considering snow cover and ablation. (c1) Cross section through the ablation area with constant cold-layer thickness and variable snow cover. (c2) Summer ablation will remove the snow cover and part of the cold surface layer, and as a result (c3) thicker cold layer will be found in areas with thicker snow cover. $(\mathrm{d} 1, \mathrm{~d} 2)$ Schematic evolution of cold-layer thickness considering that (d1) the downward migration of the CTS will (d2) thicken the layer.

The schematic evolution of a cold layer shown in Figure 5 can be summarized in this way: The rate of changes in coldlayer thickness is a balance between loss due to summer ablation (Fig. 5b) and gain due to the downward migration of the CTS (Fig. 5d). Thinning of the cold layer over time occurs when ablation is higher than downward migration. This statement is supported by direct measurements at Storglaciären since net thinning in the ablation area of $\sim 2 \mathrm{~m} \mathrm{a}^{-1}$ (Jansson and Petersson, 2007) has only partly been balanced by CTS migration rates of $\sim 1 \mathrm{~m} \mathrm{a}^{-1}$ (Pettersson and others, 2004; Gusmeroli and others, 2010). This simple and crude calculation explains most of the $0.80 \mathrm{~m} \mathrm{a}^{-1}$ thinning rate measured in Figure 4.

Ultimately, climate is the dominant control on cold-layer thickness (Pettersson and others, 2007). The presence of permanently cold ice is itself caused by particularly cold winter temperatures, and the thickness of the cold ice is primarily determined by the temperature gradient throughout the cold layer. The stronger the gradient (e.g. the lower the average winter temperature) the thicker the layer. Climatic changes affecting Storglaciären over our 20 year study period can be inferred from temperature measurements made at nearby Tarfala Research Station (Fig. 7). An increase of $1^{\circ} \mathrm{C}$ in winter air temperature since the mid1980s was proposed as the main cause of the cold-layer thinning between 1989 and 2001 (Pettersson and others, 2003, 2007). The increase in winter temperatures weakens the temperature gradient within the cold layer, in turn slowing down the downward migration of the CTS (Fig. 5). Summer temperature is also important for the cold-layer thinning. In warmer summers (e.g. 2002 and 2006 in Fig. 7) the thinning of the cold layer is likely to be accelerated because of ablation. Although the three data points in Figure 4 are clearly not enough to speculate on the trend of cold-layer thinning, we might argue that the thinning is slightly accelerated in the second period and such an enhanced thinning can be explained by the larger ablation rates experienced by the glacier after 2001.

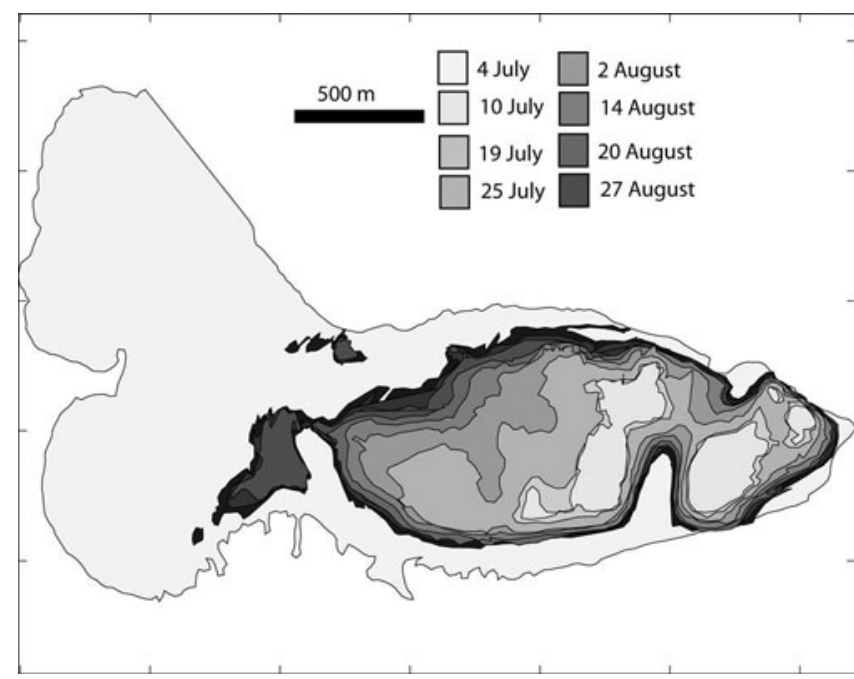

Fig. 6. Example of the evolution of the transient snowline at Storglaciären in summer 2000. The colors indicate bare ice exposed at the date of the survey. 


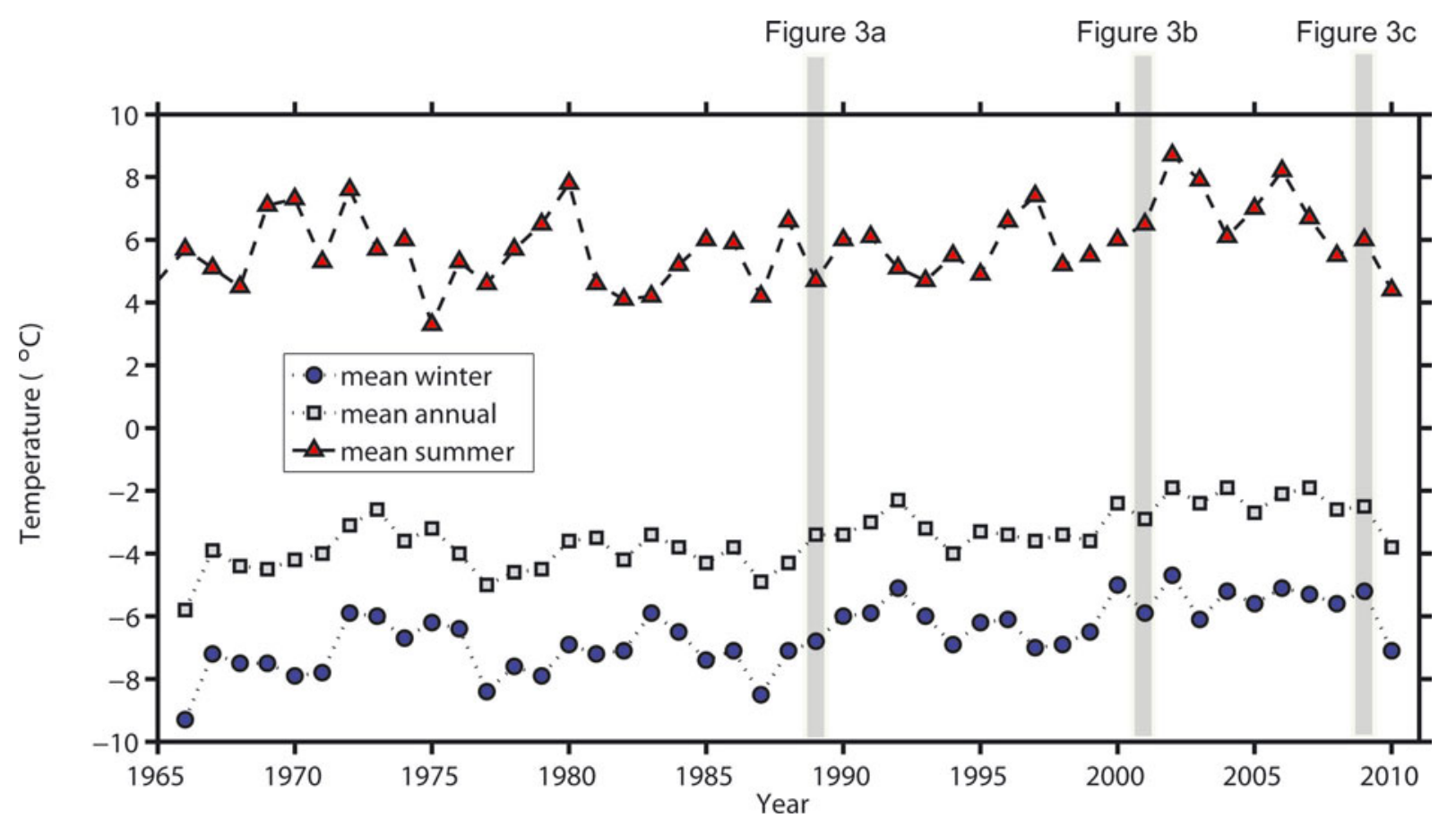

Fig. 7. 1965-2010 air temperatures at Tarfala Research Station. Circles, squares and triangles are mean winter, mean annual and mean summer temperature respectively. Vertical lines provide reference for the cold-layer map collected in 1989 (Fig. 3a), 2001 (Fig. 3b) and 2009 (Fig. 3c).

\subsection{The concept of monitoring thermal changes}

Perennial cold surface layers are also found in many other glaciated areas such as Svalbard (Björnsson and others, 1996), the European Alps (Eisen and others, 2009), Arctic Alaska (Rabus and Echelmeyer, 2002), sub-Arctic Alaska (Harrison and others, 1975; Gusmeroli unpublished radar observations, 2011), the Canadian Rockies (Paterson, 1972) and China (Huang, 1990). Studies of englacial temperatures (Rabus and Echelmeyer, 2002; Vincent and others, 2007) have shown that repeated measurements offer the opportunity to evaluate climate change in glaciated areas. Making direct measurements of glacier temperatures is, however, laborious and time-consuming, and especially challenging to implement in remote areas. Radar measurements, however, are relatively easy to obtain, and data acquisition in remote areas can be conducted efficiently from airborne platforms. We propose, therefore, that repeated measurements of thermal structures in glaciers offer an easily obtainable parameter that can be used as a proxy for evaluating glacier responses to climate change. Such observations could be incorporated with relative ease into existing mass-balance monitoring efforts in the world's glaciated regions.

\section{CONCLUSIONS}

In this paper, we have demonstrated that repeated icepenetrating radar surveys over the ablation area of polythermal glaciers can provide an additional parameter to extract a climatological signal in glaciated areas. We have presented the first time series of thermal changes in a polythermal glacier, evaluated from surveys conducted in 1989, 2001 and 2009. From our analysis we conclude that the cold surface layer of Storglaciären has been experiencing a continuous thinning at a rate that seems largely unchanged since 1989 (Fig. 4). The cold layer is slowly but consistently thinning at an average rate of $0.80 \mathrm{~m} \mathrm{a}^{-1}$.
We explain such a thinning rate by considering the two prominent factors that control cold-layer thickness (Pettersson and others, 2007). These two counteracting factors are (1) ablation-induced upward thinning $\left(2 \mathrm{~m} \mathrm{a}^{-1}\right.$; Jansson and Pettersson, 2007) and (2) temperature-controlled downward migration of the freezing front $\left(1 \mathrm{~m} \mathrm{a}^{-1}\right.$; Pettersson and others, 2004; Gusmeroli and others, 2010). In a warming climate, factor 1 is enhanced and not balanced by factor 2 . Conversely, in cold climates low surface ablation rates and higher downward migration of the cold-temperate transition would result in thickening of the layer. We believe that the thinning of the cold layer of Storglaciären is connected to the climatic warming experienced by subArctic Scandinavia since the 1980 s and we suggest that monitoring studies of the cold surface layer of polythermal glaciers will offer an additional proxy to evaluate glacier response to changes in climate.

\section{ACKNOWLEDGEMENTS}

A.G. was funded by a Swansea University postgraduate scholarship. Financial support was provided to P.J. by Swedish Research Council grant 621-2007-37252B. Partial support to A.G. and T.M. was provided by the US National Geographic Society (grant 8647-09), the Jeremy Willson Charitable Trust, the Consorzio dei Comuni del Bacino Imbrifero Montano dell'Adda, the Percy Sladen Memorial Fund, the Mount Everest Foundation, the British Society for Geomorphology, the Quaternary Research Association, the Dudley Stamp Memorial Fund and the Earth and Space Foundation. Tarfala Research Station provided fundamental logistics. C. Helanow, R. Scotti, M. Fransci, T. Enzinger and D. Hjelm all helped with the data acquisition. Data for Figure 6 were collected by C. Sturm. We are grateful to P. Holmlund, C. Vincent, A. Aschwanden and W. Harrison for helpful advice and inspirational conversations on the thermal state of glaciers. Support from A.D. Booth, 
B.E. Barrett, B. Kulessa and R.A. Clark in processing and plotting the radar data is gratefully acknowledged. Comments from our editor D. Rippin, H. Blatter, T. Phillips, D. Benn, A. Fountain, M. Funk and three anonymous reviewers greatly improved the manuscript.

\section{REFERENCES}

Aschwanden A and Blatter H (2009) Mathematical modeling and numerical simulation of polythermal glaciers. J. Geophys. Res., 114(F1), F01027 (doi: 10.1029/2008JF001028)

Barrett BE, Nicholls KW, Murray T, Smith AM and Vaughan D (2009) Rapid recent warming on Rutford Ice Stream, West Antarctica, from borehole thermometry. Geophys. Res. Lett., 36(2), L02708 (doi: 10.1029/2008GL036369)

Björnsson $\mathrm{H}$ and 6 others (1996) The thermal regime of sub-polar glaciers mapped by multi-frequency radio-echo sounding. J. Glaciol., 42(140), 23-32

Blatter H (1987) On the thermal regime of an Arctic valley glacier: a study of White Glacier, Axel Heiberg Island, N.W.T., Canada. J. Glaciol., 33(114), 200-211

Blatter H and Hutter K (1991) Polythermal conditions in Arctic glaciers. J. Glaciol., 37(126), 261-269

Blatter $\mathrm{H}$ and Kappenberger G (1988) Mass balance and thermal regime of Laika ice cap, Coburg Island, N.W.T., Canada. J. Glaciol., 34(116), 102-110

Eisen O, Bauder A, Lüthi M, Riesen P and Funk M (2009) Deducing the thermal structure in the tongue of Gornergletscher, Switzerland, from radar surveys and borehole measurements. Ann. Glaciol., 50(51), 63-70

Fountain AG, Jacobel RW, Schlichting R and Jansson P (2005) Fractures as the main pathways of water flow in temperate glaciers. Nature, 433(7026), 618-621

Gilbert A, Wagnon P, Vincent C, Ginot P and Funk M (2010) Atmospheric warming at a high-elevation tropical site revealed by englacial temperatures at Illimani, Bolivia (6340 $\mathrm{m}$ above sea level, $\left.16^{\circ} \mathrm{S}, 67^{\circ} \mathrm{W}\right)$. J. Geophys. Res., 115(D10), D10109 (doi: 10.1029/2009JD012961)

Gusmeroli A (2010) Polythermal glacier dynamics at Storglaciären, Arctic Sweden, inferred using in situ geophysical techniques. (PhD thesis, Swansea University)

Gusmeroli A, Murray T, Jansson P, Pettersson R, Aschwanden A and Booth AD (2010) Vertical distribution of water within the polythermal Storglaciären, Sweden. J. Geophys. Res., 115(F4), F04002 (doi: 10.1029/2009JF001539)

Harrison WD, Mayo LR and Trabant DC (1975) Temperature measurements on Black Rapids Glacier, Alaska, 1973. In Weller G and Bowling SA eds. Climate of the Arctic. Geophysical Institute, University of Alaska, Fairbanks, AK, 350-352

Holmlund $\mathrm{P}$ and Eriksson $\mathrm{M}$ (1989) The cold surface layer on Storglaciären. Geogr. Ann., Ser. A, 71(3-4), 241-244

Holmlund $\mathrm{P}$, Jansson $\mathrm{P}$ and Pettersson $\mathrm{R}$ (2005) A re-analysis of the 58 year mass-balance record of Storglaciären, Sweden. Ann. Glaciol., 42, 389-394

Hooke RLeB, Gould JE and Brzozowski J (1983) Near-surface temperatures near and below the equilibrium line on polar and subpolar glaciers. Z. Gletscherkd. Glazialgeol., 19(1), 1-25

Huang M (1990) On the temperature distribution of glaciers in China. J. Glaciol., 36(123), 210-216

Huggel C (2009) Recent extreme slope failures in glacial environments: effects of thermal perturbation. Quat. Sci. Rev., 28(11-12), 1119-1130

Huss M (2011) Present and future contribution of glacier storage change to runoff from macroscale drainage basins in Europe.
Water Resour. Res., 47(W7), W07511 (doi: 10.1029/ 2010WR010299)

Hutter K, Blatter $\mathrm{H}$ and Funk M (1988) A model computation of moisture content in polythermal glaciers. J. Geophys. Res., 93(B10), 12 205-12 214

Isaaks EH and Srivastava RM (1989) An introduction to applied geostatistics. Oxford University Press, New York

Iverson NR, Hanson B, Hooke RLeB and Jansson P (1995) Flow mechanism of glaciers on soft beds. Science, 267(5194), 80-81

Jansson P and Pettersson P (2007) Spatial and temporal characteristics of a long mass balance record, Storglaciären, Sweden. Arct. Antarct. Alp. Res., 39(3), 432-437

Jarvis GT and Clarke GKC (1974) Thermal effects of crevassing on Steele Glacier, Yukon Territory, Canada. J. Glaciol., 13(68), 243-254

Le Meur E and Vincent C (2006) Monitoring of the Taconnaz ice fall (French Alps) using measurements of mass balance, surface velocities and ice cliff position. Cold Reg. Sci. Technol., 46(1), $1-11$

Lemke P and 10 others (2007) Observations: changes in snow, ice and frozen ground. In Solomon $\mathrm{S}$ and 7 others eds. Climate change 2007: the physical science basis. Contribution of Working Group I to the Fourth Assessment Report of the Intergovernmental Panel on Climate Change. Cambridge University Press, Cambridge, 339-383

Murray T and 6 others (2000) Glacier surge propagation by thermal evolution at the bed. J. Geophys. Res., 105(B6), 13 491-13 507

Ødegård RS, Hagen $\mathrm{JO}$ and Hamran SE (1997) Comparison of radio-echo sounding $(30-1000 \mathrm{MHz})$ and high-resolution borehole-temperature measurements at Finsterwalderbreen, southern Spitsbergen, Svalbard. Ann. Glaciol., 24, 262-267

Paterson WSB (1972) Temperature distribution in the upper layers of the ablation area of Athabasca Glacier, Alberta, Canada. J. Glaciol., 11(61), 31-41

Pettersson R (2005) Frequency dependence of scattering from the cold-temperate transition surface in a polythermal glacier. Radio Sci., 40(3), RS3007 (doi: 10.1029/2004RS003090)

Pettersson R, Jansson P and Holmlund P (2003) Cold surface layer thinning on Storglaciären, Sweden, observed by repeated ground penetrating radar surveys. J. Geophys. Res., 108(F1), 6004 (doi: 10.1029/2003JF000024)

Pettersson R, Jansson P and Blatter H (2004) Spatial variability in water content at the cold-temperate transition surface of the polythermal Storglaciären, Sweden. J. Geophys. Res., 109(F2), F02009 (doi: 10.1029/2003JF000110)

Pettersson R, Jansson P, Huwald H and Blatter H (2007) Spatial pattern and stability of the cold surface layer of Storglaciären, Sweden. J. Glaciol., 53(180), 99-109

Rabus BT and Echelmeyer KA (2002) Increase of $10 \mathrm{~m}$ ice temperature: climate warming or glacier thinning? J. Glaciol., 48(161), 279-286

Radić V and Hock R (2011) Regionally differentiated contribution of mountain glaciers and ice caps to future sea-level rise. Nature Geosci., 4(2), 91-94

Rippin DM, Carrivick JL and Williams C (2011) Evidence towards a thermal lag in the response of Kårsaglaciären, northern Sweden, to climate change. J. Glaciol., 57(205), 895-903

Schytt V (1968) Notes on glaciological activities in Kebnekaise, Sweden during 1966 and 1967. Geogr. Ann., 50A(2), 111-120

Vincent C, Le Meur E, Six D, Possenti P, Lefebvre E and Funk M (2007) Climate warming revealed by englacial temperatures at Col du Dôme (4250 m, Mont Blanc area). Geophys. Res. Lett., 34(16), L16502 (doi: 10.1029/2007GL029933)

Wohlleben T, Sharp M and Bush A (2009) Factors influencing the basal temperatures of a High Arctic polythermal glacier. Ann. Glaciol., 50(52), 9-16 